\title{
Relação custo-benefício dos incentivos fiscais: Um estudo baseado na DVA de empresas calçadistas incentivadas
}

Clovis Antônio Kronbauer Doutorado em Contabilidade e Auditoria pela Universidade de Sevilha (Espanha) Professor da Universidade do Vale do Rio dos Sinos - UNISINOS Av. Unisinos, 950. Bairro Cristo Rei. São Leopoldo/RS. CEP: 93022-000 E-mail: clovisk@unisinos.br

Luiz Carlos Schneider Mestrado em Ciências Contábeis com Ênfase Controladoria e Finanças pela Universidade do Vale do Rio dos Sinos - UNISINOS Av. Unisinos, 950. Bairro Cristo Rei. São Leopoldo/RS. CEP: 93022-000 E-mail:schneider.luizc@gmail.com

Leandro Lumieri Mestrado em andamento em Ciências Contábeis pela Universidade do Vale dos Sinos - UNISINOS Av. Unisinos, 950. Bairro Cristo Rei. São Leopoldo/RS. CEP: 93022-000 E-mail: lumbieri@terra.com.br

Fernando Andrade Pereira Mestrado em andamento em Ciências Contábeis pela Universidade do Vale dos Sinos - UNISINOS

Av. Unisinos, 950. Bairro Cristo Rei. São Leopoldo/RS. CEP: 93022-000 E-mail: pereiranando@bol.com.br

João Zani Doutor em Administração pela Universidade Federal do Rio Grande do Sul - UFRGS Professor da Universidade do Vale do Rio dos Sinos - UNISINOS Av. Unisinos, 950. Bairro Cristo Rei. São Leopoldo/RS. CEP: 93022-000 E-mail: jzani@unisinos.br

\section{RESUMO}

O objetivo deste estudo é avaliar os benefícios que a concessão de incentivos fiscais pode trazer ao entorno social no qual se instalam empresas incentivadas. Esta avaliação se realiza a partir da análise do Índice de Custo-Benefício dos Incentivos Fiscais (ICBIF) calculado a partir da DVA. Também se realizou análise de indicadores financeiros e econômicos das empresas incentivadas, para avaliar sua evolução financeira e econômica a partir do recebimento de incentivos fiscais. Analisou-se, ainda, a evolução da arrecadação total de impostos dos municípios nos quais as empresas se instalaram, buscando averiguar possíveis repercussões na economia local a partir da instalação das empresas incentivadas. Quanto à metodologia, esta pesquisa caracteriza-se como aplicada, visto que o objeto de estudo é o caso de duas empresas do setor calçadista. Pela forma de obtenção dos dados, a pesquisa 
Relação custo-benefício dos incentivos fiscais: Um estudo baseado na DVA de empresas calçadistas incentivadas Clovis Antônio Kronbauer, Luiz Carlos Schneider, Leandro Lumieri, Fernando Andrade Pereira, João

enquadra-se como documental e as técnicas de análise apresentam predominância qualitativa. Como resultado do estudo observou-se que as empresas incentivadas retornaram à sociedade local um valor adicionado superior ao investido pelo governo a título de incentivo fiscal. Os municípios onde estas empresas se instalaram, registraram um aumento de arrecadação, podendo-se relacionar à política de concessão de incentivos fiscais que atraíram a instalação das empresas objeto do estudo. Percebeu-se também, que as empresas possuem uma situação financeira e econômica estável, ou seja, empresas e municípios obtiveram benefícios com a política de concessão de incentivos fiscais.

Palavras-chave: Incentivos Fiscais. Valor Adicionado. Índice de Custo-Benefício dos Incentivos Fiscais (ICBIF).

\section{Cost-Benefit tax incentives: A study based on DVA of incentives footwear companies}

\section{ABSTRACT}

The objective of this study is to evaluate the benefits that tax incentives can bring to the social environment in which companies settle encouraged. This evaluation is carried from the analysis of the Index of Cost-Benefit Tax Incentives (ICBIF) calculated from the DVA. Also performed analysis of financial and economic enterprises encouraged to evaluate their financial and economic developments of the receipt of tax incentives. It was also analyzed the evolution of total tax revenues of the municipalities in which the companies have settled, seeking to investigate possible effects on the local economy from the location of business incentives. Regarding the methodology, this research is characterized as applied, since the object of study is the case of two companies in the footwear industry. By way of obtaining data, the research fits the documentary and analysis techniques are predominantly qualitative. As a result of the study notes that encouraged companies returned to the local society more than they invested by the government as a tax incentive. The municipalities where these companies have settled, recorded an increase in collection, can be related to the policy of granting tax incentives to attract companies to install the object of study. It is also evident that companies have a stable financial and economic situation, if, businesses and municipalities have obtained benefits from the policy of granting tax incentives.

Key words: Tax Incentives. Added Value. Index of Cost-Benefit Tax Incentives (ICBIF).

\section{INTRODUÇÃO}

A preocupação com o desenvolvimento de determinadas regiões tem levado os governos (federal, estaduais e municipais) a atrair empresas por meio da concessão 
Relação custo-benefício dos incentivos fiscais: Um estudo baseado na DVA de empresas

calçadistas incentivadas

Clovis Antônio Kronbauer, Luiz Carlos Schneider, Leandro Lumieri, Fernando Andrade Pereira, João

Zani

de incentivos fiscais. Apesar de serem constantemente questionados, os incentivos fiscais têm amparo legal, embora em algumas situações possa não ocorrer uma avaliação mais aprofundada quanto aos benefícios sociais gerados por estas políticas.

O estudo envolve o tema conhecido como "guerra fiscal" entre as unidades federativas no Brasil. Nesta disputa, observam-se numa determinada posição os estados que concedem incentivos fiscais justificando ser a única forma de desenvolver regiões mais pobres por meio da atração de indústrias. Em contraposição, as demais unidades federativas que não utilizam tais políticas adotam uma postura crítica, revelando estarem sofrendo prejuízos com a migração de indústrias que mudam suas unidades para os estados incentivadores.

Neste sentido, conforme destaca Rodrigues Jr. (2003), um dos casos mais polêmicos envolveu a montadora Ford e o governo do estado da Bahia. A concessão de incentivos fiscais federais e estaduais, além de financiamentos do BNDES, para a instalação da montadora provocou muitos questionamentos, principalmente por parte do governo do estado de São Paulo, de onde esta unidade da Ford se transferira.

O fator incentivo fiscal é apenas uma forma de atrair empresas para desenvolver determinada região, mas outros aspectos também podem contribuir para que uma empresa opte por abandonar sua sede inicial e mudar-se para outro estado. Dentre estes fatores, Prado e Cavalcanti (2000) identificaram com a mesma importância dos incentivos fiscais, os fatores da proximidade do mercado e o custo da mão de obra.

Assim, objetivando identificar se a concessão de incentivos fiscais beneficia a sociedade local, este estudo confronta o montante dos incentivos fiscais concedidos com o valor adicionado e os benefícios sociais gerados por duas empresas do setor calçadista beneficiadas por este tipo de incentivos.

Para avaliar se a relação de custo e benefício dos investimentos feitos a título de incentivos fiscais reverte em desenvolvimento para as regiões incentivadoras, a análise realizada está baseada na Demonstração do Valor Adicionado (DVA), nas demonstrações contábeis e nas receitas dos impostos gerados aos municípios das empresas beneficiadas e que são o objeto deste estudo. 
Relação custo-benefício dos incentivos fiscais: Um estudo baseado na DVA de empresas

calçadistas incentivadas

Clovis Antônio Kronbauer, Luiz Carlos Schneider, Leandro Lumieri, Fernando Andrade Pereira, João

\section{REFERENCIAL TEÓRICO}

\subsection{Incentivos fiscais}

Ao longo do tempo, a política econômica das unidades federativas brasileiras tem passado por grandes transformações, quer por decisões políticas ou macro econômicas. De acordo com Scipião (2004), têm ocorrido mudanças na relação do governo federal com os governos estaduais e municipais, sendo que nas décadas de 1980 e 1990 quatro elementos-chave contribuíram para estas mudanças: (1) as diretrizes da Constituição Federal de 1988, incentivando o processo de descentralização e desconcentração de recursos e decisões para os governos locais; (2) a reforma do Estado, que passa a assumir crescente papel normativo e regulatório, delegando aos governos locais o papel executivo e de supervisão; (3) a crise fiscal do Estado forçando a busca por parcerias junto a iniciativa privada e a sociedade civil na busca de soluções para os problemas enfrentados em âmbito local; e (4) o processo de globalização e as exigências de inserção competitiva na economia globalizada que recolocam a importância de valorizar-se o espaço local.

Em função dessas mudanças, os governos vêm implantando políticas de concessão de incentivos fiscais para desenvolver determinadas regiões. A concessão dos incentivos vem cumprindo seu papel de descentralização dos polos industriais. $\mathrm{O}$ progresso das regiões incentivadas fiscalmente pode ser percebido pelo desenvolvimento das cidades, que se tornam centros de concorrência e progresso, criando-se novas possibilidades para o aprimoramento do bem-estar da população em geral, em decorrência do processo de industrialização proporcionado pelos incentivos fiscais concedidos (PINHO; VASCONCELOS, 1990).

O fator motivador para concessão de incentivos fiscais surge com a Constituição Federal (CF) de 1988 ao atribuir a cada estado o poder de fixar autonomamente as alíquotas do Imposto sobre Circulação de Mercadorias e Serviços (ICMS), visto que este imposto se constitui na base da receita estadual. Desta forma, conforme refere Dulci (2002), estava preparado o alicerce jurídico para a guerra fiscal 
Relação custo-benefício dos incentivos fiscais: Um estudo baseado na DVA de empresas calçadistas incentivadas Clovis Antônio Kronbauer, Luiz Carlos Schneider, Leandro Lumieri, Fernando Andrade Pereira, João

acirrando as disputas entre os estados por oportunidades e meios de desenvolvimento, oportunizados, também, pela abertura da economia brasileira, o que propiciou um ambiente econômico que atraiu um fluxo crescente de capitais internacionais. No que se refere ao acesso aos incentivos fiscais, Matkin (2010) refere que as empresas com melhor acesso aos conhecimentos fiscais podem ter vantagens não intencionais sobre outras empresas menos estruturadas sobre este tema.

Nascimento (2009) aborda os impactos positivos e negativos da concessão de incentivos fiscais pela ótica do administrador público. Os aspectos positivos seriam a geração de empregos e renda, o crescimento do PIB local, bem como da receita tributária futura. Os principais ônus seriam os conflitos entre os entes federados e a perda de receita presente, que poderá não ser compensada no futuro, pois existe a possibilidade das empresas migrarem para outros estados após o período de carência, sem a recuperação dos recursos aplicados pelo Estado.

Para Matkin (2010), as políticas de incentivos fiscais muitas vezes não surtem efeitos positivos, pois não afetam as decisões de investimento e, portanto, torna-se desnecessário reduzir as receitas fiscais. Em contrapartida, os programas de incentivos fiscais podem ser eficazes se devidamente planejados, com estrutura de prestação de contas e acompanhamento dos resultados do desenvolvimento empresarial e regional.

Contudo, de acordo com Rodrigues Jr. (2003), tem havido contestações no que se refere à concessão destes incentivos, questionando-se os resultados efetivos principalmente com sua finalidade principal, que seria a geração de empregos. Seguindo o mesmo raciocínio, Viol (1999) destaca que o crescimento econômico por meio de incentivos fiscais, não gera necessariamente melhoria nas condições de vida da população.

De acordo com a Constituição Federal (CF) de 1988, Art. 158, pertencem aos municípios, $25 \%$ da receita de arrecadação do ICMS e estas parcelas serão creditadas conforme critérios: I - três quartos, no mínimo, na proporção do Valor Adicionado nas operações relativas ao ICMS; e, II - até um quarto, de acordo com o que dispuser lei 
Relação custo-benefício dos incentivos fiscais: Um estudo baseado na DVA de empresas calçadistas incentivadas Clovis Antônio Kronbauer, Luiz Carlos Schneider, Leandro Lumieri, Fernando Andrade Pereira, João

Estadual. Assim, a geração de valor adicionado aos municípios, e por consequência para os Estados, aumenta a arrecadação fiscal e motiva a concessão de incentivos.

Mesmo assim, cabe avaliar, além da questão da promoção do desenvolvimento das regiões, o valor econômico gerado, a partir da visão do valor adicionado, além de refletir sobre benefícios gerados às empresas incentivadas, em sua situação econômica e financeira.

$\mathrm{Na}$ seção seguinte abordam-se os aspectos sobre o valor adicionado e a Demonstração do Valor Adicionado (DVA).

\subsection{Valor adicionado e Demonstração do Valor Adicionado (DVA)}

O valor adicionado pode ser analisado de várias formas, destacando-se neste estudo os enfoques de natureza fiscal e econômica, aplicados às entidades empresariais.

De acordo com Soares (2009), o Valor Adicionado Fiscal (VAF), é um indicador econômico-contábil utilizado pelos Estados (unidades federativas) para calcular o índice de participação municipal no repasse de receita do ICMS aos municípios. O VAF é apurado pelas Secretarias da Fazenda dos estados membros, com base em declarações anuais apresentadas pelas empresas estabelecidas nos respectivos municípios. O Valor Adicionado Fiscal é o resultado do movimento econômico de um determinado contribuinte em um exercício e sua forma de cálculo se dá pela adição das mercadorias saídas à prestação de serviços tributáveis pelo ICMS, deduzindo-se as mercadorias entradas e serviços utilizados.

O VAF é utilizado para fins de repartição de receitas fiscais, mas constitui-se em instrumento de controle interno que é reportado ao fisco, logo, não disponível aos usuários externos. Assim, segundo Tinoco (2001), uma das formas que amplia a capacidade de se analisar o desempenho econômico e social das organizações ocorre por meio do valor econômico que é agregado aos bens e serviços adquiridos de terceiros, sendo este valor denominado Valor Adicionado ou Valor Agregado. Este indicador é calculado pela soma do valor total da produção de bens e serviços de um determinado período, deduzidos dos custos dos recursos adquiridos de terceiros 
Relação custo-benefício dos incentivos fiscais: Um estudo baseado na DVA de empresas calçadistas incentivadas Clovis Antônio Kronbauer, Luiz Carlos Schneider, Leandro Lumieri, Fernando Andrade Pereira, João

necessários a esta produção, englobando também a forma pela qual este está sendo distribuído entre os diferentes grupos sociais, que interagem com suas atividades.

Observando os dois conceitos de valor adicionado, percebe-se uma compatibilidade entre o VAF e o Valor Agregado Econômico. Logo, este segundo, que atualmente tem sua divulgação exigida pela Lei 11.638/2007, por meio da Demonstração do Valor Adicionado - DVA pode ser utilizado para instrumento de análise ao presente objeto de estudo.

Para ludícibus (2006), a divulgação da DVA pode contribuir para que os economistas governamentais tenham informações mais amoldadas para o cálculo das contas nacionais, ampliando a gama de informações contábeis relevantes, não somente para finalidades macroeconômicas, mas enquadrando-se no cenário mais amplo da Contabilidade Social. Para tanto, a DVA procura comparar o valor das vendas de uma entidade com o custo dos insumos adquiridos fora da empresa, tanto em forma de produtos como serviços, sobre os quais a entidade (empresa) adicionou valor.

Caso todas as atividades econômicas desenvolvidas no País fossem desenroladas em entidades que levantassem demonstrações a valor adicionado, a consolidação de tais demonstrações, excluídas as duplas contagens, já seria o próprio Produto Interno Bruto - PIB, muito mais corretamente estimado do que atualmente. Assim, poder-se-ia avaliar a contribuição de cada empresa para o PIB nacional (COSTEIRA, 2005).

O surgimento da Demonstração do Valor Adicionado - DVA está diretamente atrelado a necessidade de serem elaboradas informações de como a riqueza é gerada pelas empresas, e de como ocorre a sua utilização e distribuição entre os diversos agentes que contribuíram na sua geração (KROETZ; NEUMANN; FILIPIN, 2008).

A apresentação da DVA pode propiciar vantagens para as empresas que a publicam. Santos (1999) exemplifica que uma empresa multinacional poderia beneficiar-se com a divulgação da DVA, como sendo uma oportunidade de apresentar sua contribuição ao país na qual esteja sediada. A empresa multinacional pode utilizar essa demonstração para estabelecer o interesse da comunidade e de seus 
Relação custo-benefício dos incentivos fiscais: Um estudo baseado na DVA de empresas calçadistas incentivadas Clovis Antônio Kronbauer, Luiz Carlos Schneider, Leandro Lumieri, Fernando Andrade Pereira, João

legisladores, oportunizando a formação de goodwill, expansão do mercado, redução de conflitos com o governo local e outros grupos da sociedade, e evitaria diversos desgastes políticos, até no que se refere a eventuais incentivos fiscais recebidos. Como consequência disso, a empresa provavelmente alcançaria maior crescimento e estabilidade de seus lucros.

Na mesma linha de raciocínio, o Comitê de Pronunciamentos Contábeis - CPC em pronunciamento técnico denominado CPC - 09 (artigo 176 - V), refere que a DVA é um braço do Balanço Social, pois apresenta a divisão da riqueza produzida pela empresa e a sua destinação à sociedade. Desta forma o principal objetivo é demonstrar o grau de envolvimento da empresa em relação à sociedade que a acolhe, ou seja, "é um poderoso referencial de informações nas políticas de recursos humanos, nas decisões de incentivos fiscais, no auxilio sobre novos investimentos e no desenvolvimento de consciência para a cidadania".

A partir das alterações introduzidas pela lei $n^{\circ} 11.638 / 2007$, tornou-se obrigatória a publicação desta demonstração, inicialmente para todas as sociedades anônimas de capital aberto. Contudo, a partir do exercício de 2010, esta obrigatoriedade entendeu-se para as sociedades anônimas de capital fechado.

A DVA, como demonstração que evidencia o montante de valor adicionado gerado pela entidade, constitui-se num elemento que pode revelar o retorno gerado para a sociedade que incentivou um determinado empreendimento por meio de recursos públicos, ou seja, os incentivos fiscais. Rodrigues Jr. (2003) realizou estudo analisando o custo-benefício da concessão de incentivos fiscais em duas empresas do setor têxtil, no estado do Ceará. Os resultados revelaram que o valor adicionado gerado foi em média de cinco a seis vezes o valor do incentivo concedido, além de benefícios adicionais gerados a região na qual se instalaram as empresas. Assim, replica-se este estudo em outras duas empresas, do setor calçadista, que também foram incentivadas e que se instalaram nos municípios de Sobral e Horizonte, no Ceará. 
Relação custo-benefício dos incentivos fiscais: Um estudo baseado na DVA de empresas calçadistas incentivadas Clovis Antônio Kronbauer, Luiz Carlos Schneider, Leandro Lumieri, Fernando Andrade Pereira, João

\section{METODOLOGIA}

Por sua natureza, a pesquisa caracteriza-se como aplicada, visto que o objeto de estudo são duas empresas do setor calçadista que foram beneficiadas por políticas de incentivos fiscais, para instalarem unidades fabris em cidades do estado do Ceará. Pela forma de obtenção dos dados, a pesquisa enquadra-se como documental, pois as informações analisadas foram coletadas das demonstrações contábeis consolidadas das empresas, que se encontram publicadas na página web da Comissão de Valores Mobiliários - CVM, tendo sido ainda obtidos dados diretamente com as empresas.

Para analisar os dados obtidos, utilizaram-se técnicas de análise descritiva do conteúdo da DVA e das Demonstrações Contábeis. Sob este aspecto, a pesquisa reveste-se de características descritivas e as técnicas de análise apresentam predominância qualitativa, fazendo com que a pesquisa assuma características qualitativas no que se refere à abordagem do problema.

Para analisar os dados, primeiramente procedeu-se na sumarização e descrição das demonstrações de valor adicionado das empresas, quantificando e relativizando o valor adicionado distribuído. Na sequencia, calculou-se, como base no estudo de Rodrigues Jr. (2003) os diversos índices de Custo-Benefício dos Incentivos fiscais. Para tanto foram calculados: a) Índice de Custo-Benefício Geral (ICB Geral), dividindo o Valor Adicionado Distribuído pelo Benefício Fiscal; b) Índice de CustoBenefício Social (ICB Social), dividindo o Valor Adicionado Distribuído a Pessoal e Tributos pelo Benefício Fiscal; e, c) Índice de Custo-Benefício dos Acionistas (ICB Acionistas), dividindo o Valor Adicionado de Lucros e Dividendos pelo Benefício Fiscal.

Pela análise destes índices, buscou-se avaliar os eventuais benefícios gerados pelos incentivos fiscais, a partir do valor adicionado distribuído pelas empresas incentivadas, a partir das demonstrações contábeis consolidadas.

Também se realizou análise de indicadores financeiros e econômicos das empresas, para avaliar a sua evolução a partir do recebimento de incentivos fiscais. Para tanto, utilizou-se indicadores de análise de demonstrações contábeis 
Relação custo-benefício dos incentivos fiscais: Um estudo baseado na DVA de empresas calçadistas incentivadas Clovis Antônio Kronbauer, Luiz Carlos Schneider, Leandro Lumieri, Fernando Andrade Pereira, João

apresentados por Matarazzo (2010), avaliando: Liquidez Geral, Liquidez Corrente, Endividamento, Margem Líquida, Rentabilidade sobre o Patrimônio Líquido, Valor Patrimonial da Ação e Lucro por Ação.

Por fim, analisou-se a evolução da arrecadação total de impostos dos municípios nos quais as empresas se instalaram, buscando averiguar possíveis repercussões na economia local a partir da instalação das empresas incentivadas. Segundo Yin (2010), a análise de dados consiste em examinar, categorizar, classificar em tabelas, ou ao contrário, recombinar as evidências tendo em vista proposição inicial de um estudo. O desafio é produzir análises de alta qualidade considerando todas as evidências coletadas. As empresas objeto deste estudo são:

- Empresa Grendene, fundada em 1971, é uma das maiores produtoras mundiais de calçados sintéticos e líder em vários segmentos no mercado brasileiro. Para instalar-se no município de Sobral-CE foi beneficiada com incentivos fiscais federais (redução ou isenção do IRPJ) e estaduais, com a restituição de parte do valor de ICMS recolhido ao Estado do Ceará e do valor de exportação de produtos; e;

- Empresa Vulcabrás Azaléia, constitui-se na maior indústria de calçados e material esportivo da América Latina e conta com um portfólio completo para o consumidor, com marcas líderes no Brasil e exterior. Para instalar-se no município de HorizonteCE, também foi beneficiada por incentivos fiscais federais e estaduais idênticos aos da Empresa Grendene.

O período de análise compreende os exercícios sociais de 2007, 2008 e 2009. Na sequência são apresentadas as análises dos dados da pesquisa.

\section{ANÁLISE DOS DADOS}

\subsection{Valores adicionados gerados pelas empresas analisadas}

\subsubsection{Análise do valor adicionado da empresa Grendene}

$\mathrm{Na}$ Tabela 1 são apresentados os itens inerentes ao valor adicionado gerado e distribuído pela Grendene a partir da DVA dos anos de 2007 a 2009. A partir desta tabela percebe-se que o valor adicionado desta empresa registrou acréscimos 
Relação custo-benefício dos incentivos fiscais: Um estudo baseado na DVA de empresas calçadistas incentivadas

Clovis Antônio Kronbauer, Luiz Carlos Schneider, Leandro Lumieri, Fernando Andrade Pereira, João

contínuos e consecutivos em cada um dos nos três anos analisados, alcançando um valor superior a $\mathrm{R} \$ 984$ milhões em 2009.

Tabela 1: Valor Adicionado Distribuído pela Empresa Grendene (Em R\$ Mil)

\begin{tabular}{lcccccc}
\hline \multicolumn{1}{c}{ ANOS } & $\underline{2009}$ & $\underline{\%}$ & $\underline{2008}$ & $\underline{\%}$ & $\underline{2007}$ & $\underline{\%}$ \\
Distribuição do Valor Adicionado & 984.709 & 100,00 & 871.459 & 100,00 & 813.061 & 100,00 \\
\hline Pessoal e Encargos & 346.685 & 35,21 & 265.953 & 30,52 & 237.232 & 29,18 \\
Impostos, Taxas e Contribuições & 198.682 & 20,18 & 151.977 & 17,44 & 166.949 & 20,53 \\
Juros, Aluguéis e Outros & 167.131 & 16,97 & 214.162 & 24,58 & 143.511 & 17,65 \\
Lucros\Prej. Do Exerc. E Dividendos & 272.211 & 27,64 & 239.367 & 27,47 & 265.369 & 32,64 \\
\hline
\end{tabular}

Fonte: Elaborada a partir da Demonstração do Valor Adicionado da Empresa

Ainda com base na Tabela 1, percebe-se que os principais destinatários da distribuição deste valor adicionado, nos três anos analisados, são respectivamente Pessoal e Encargos e os Acionistas, sendo estes beneficiados por distribuição de lucros e dividendos. No de 2007 os acionistas foram os principais destinatários do valor adicionado distribuído, situação que se alterou em 2008 e 2009, quando os principais beneficiados pela destinação do valor agregado passaram a ser Pessoal e Encargos.

\subsubsection{Análise do valor adicionado da empresa Vulcabrás Azaléia}

$\mathrm{Na}$ tabela 2 são apresentados os itens inerentes ao valor adicionado gerado e distribuído pela Empresa Vulcabrás Azaléia a partir da DVA dos anos de 2007 a 2009.

Tabela 2: Valor Adicionado Distribuído pela Vulcabrás Azaléia (Em R\$ Mil)

\begin{tabular}{lrrrrrr}
\hline \multicolumn{1}{c}{$\underline{\text { ANOS }}$} & $\underline{2009}$ & $\underline{\underline{\%}}$ & $\underline{2008}$ & $\underline{\underline{\%}}$ & $\underline{2007}$ & $\underline{\%}$ \\
Distribuição do Valor Adicionado & 1.067 .698 & 100,00 & $\underline{999.690}$ & 100,00 & 536.659 & 100,00 \\
\hline Pessoal e Encargos & 448.517 & 42,01 & 452.842 & 45,30 & 208.242 & 38,80 \\
Impostos, Taxas e Contribuições & 306.858 & 28,74 & 282.445 & 28,25 & 257.022 & 47,89 \\
Juros, Aluguéis e Outros & 175.268 & 16,42 & 91.203 & 9,12 & 47.015 & 8,76 \\
Lucros\Prej. Do Exerc. E Dividendos & 137.055 & 12,84 & 173.200 & 17,33 & 24.380 & 4,54 \\
\hline
\end{tabular}

Fonte: Elaborada a partir da Demonstração do Valor Adicionado da Empresa

A partir da Tabela 2, observa-se que o valor adicionado gerado pela Vulcabrás Azaléia registrou crescimento contínuo nos três anos analisados, sendo o acréscimo 
Relação custo-benefício dos incentivos fiscais: Um estudo baseado na DVA de empresas calçadistas incentivadas Clovis Antônio Kronbauer, Luiz Carlos Schneider, Leandro Lumieri, Fernando Andrade Pereira, João

mais significativo registrado de 2007 para 2008, quando o referido valor agregado registrou um aumento nominal de aproximadamente $86,3 \%$. Os principais beneficiados pela distribuição do valor adicionado gerado foram: Pessoal e Encargos e Impostos, Taxas e Contribuições. Em 2007, a principal destinação do valor adicionado da empresa recaiu para Impostos, Taxas e Contribuições, mas nos dois anos seguintes, Pessoal e Encargos foram os principais destinatários do referido valor agregado.

A partir da apresentação dos dados de valor adicionado das empresas cabe comparar os mesmo com os incentivos fiscais recebidos, avaliando seus índices de custo-benefício.

\section{2 Índices de custo-benefício dos incentivos fiscais}

Por meio do cálculo dos Índices de Custo-Benefício dos Incentivos Fiscais (ICBIF) buscou-se avaliar o retorno que as empresas estudadas geraram para sociedade, a partir dos incentivos fiscais recebidos dos governos, conforme apresentado na sequência.

\subsubsection{Análise do ICBIF na empresa Grendene}

$\mathrm{Na}$ Tabela 3 são apresentados os Índices de Custo-Benefício dos Incentivos Fiscais da Empresa Grendene. Os diferentes índices foram calculados a partir dos dados da DVA e dos valores de incentivos fiscais recebidos por esta empresa, comparando-os respectivamente com o Valor Adicionado Total, Valor Adicionado destinado a Pessoal, Encargos e Tributos, e Valor Adicionado destinado a Acionistas.

Tabela 3: Índices Custo-Benefício dos Incentivos Fiscais Recebidos Grendene

\begin{tabular}{ccrrrrrr}
\hline \multirow{2}{*}{ Ano } & $\begin{array}{c}\text { Valor Adic. } \\
\text { Liq. ( 1 ) }\end{array}$ & $\begin{array}{c}\text { Pessoal e } \\
\text { Tributos (2) }\end{array}$ & $\begin{array}{c}\text { Lucros e } \\
\text { Divid. (3) }\end{array}$ & $\begin{array}{c}\text { Incentivo } \\
\text { Fiscal ( 4) }\end{array}$ & $\begin{array}{c}\text { ICB Geral } \\
(1 / 4)\end{array}$ & $\begin{array}{c}\text { ICB Social } \\
(2 / 4)\end{array}$ & $\begin{array}{c}\text { ICB } \\
\text { Acionist.(3/4) }\end{array}$ \\
\hline 2009 & 984.709 & 545.367 & 272.211 & 157.100 & 6,27 & 3,47 & 1,73 \\
2008 & 871.459 & 417.930 & 239.367 & 132.283 & 6,59 & 3,16 & 1,81 \\
2007 & 813.061 & 404.181 & 265.369 & 132.615 & 6,13 & 3,05 & 2,00 \\
Média & 889.743 & 455.826 & 258.982 & 140.666 & 6,33 & 3,24 & 1,84 \\
\hline
\end{tabular}

Fonte: Elaborado pelos autores com base na Demonstração do Valor Adicionado da Empresa 
Relação custo-benefício dos incentivos fiscais: Um estudo baseado na DVA de empresas calçadistas incentivadas Clovis Antônio Kronbauer, Luiz Carlos Schneider, Leandro Lumieri, Fernando Andrade Pereira, João

Com base na Tabela 3, observa-se que o ICB Geral médio da empresa é de 6,33 nos três anos analisados. Assim, para cada $R \$ 1,00$ recebido pela empresa a título de incentivos fiscais, houve a geração média de $\mathrm{R} \$ 6,33$ de valor adicionado. Percebe-se que o maior ICB Geral foi observado em 2008, mas que este índice se manteve acima de 6,0 nos três anos.

Também se observa que nos três anos o ICB Social médio foi de 3,24, o que reflete que para cada $R \$ 1,00$ recebido pela empresa a título de incentivos fiscais, houve a distribuição, em média de $\mathrm{R} \$ 3,33$ de valor adicionado para Pessoal, Encargos Sociais e Tributos, o que pode ser considerado como retorno social.

A partir da Tabela 3, observa-se ainda que o ICB Acionistas apresentou um valor médio de 1,84 no triênio analisado. Isto revela que em relação a cada $R \$ 1,00$ recebido pela empresa a título de incentivos fiscais, coube aos acionistas em média um valor distribuído de $\mathrm{R} \$ 1,84$, na forma de lucros retidos e dividendos. Procedendo a uma análise simplista, poder-se-ia afirmar que em média, no triênio analisado, uma proporção de $54,31 \%$ dos lucros retidos e dividendos distribuídos aos acionistas da Empresa Grendene equivalem-se aos incentivos fiscais recebidos pela empresa.

Considerando o ICB Geral e o ICB Social da empresa Grendene, pode-se inferir que os incentivos fiscais concedidos geraram um retorno significativo em termos de valor adicionado total e social. Na sequencia, apresenta-se a análise dos índices de custo-benefício dos incentivos fiscais concedidos a Empresa Vulcabrás Azaléia.

\subsubsection{Análise do ICBIF na empresa Vulcabrás Azaléia}

Da mesma forma como no caso da empresa Grendene, os diferentes índices para a empresa Vulcabrás Azaléia também foram calculados a partir dos dados da DVA e dos valores de incentivos fiscais recebidos por esta empresa, comparando-os respectivamente com o Valor Adicionado Total, Valor Adicionado destinado a Pessoal, Encargos e Tributos, e Valor Adicionado destinado a Acionistas. Na sequencia, na Tabela 4, apresentam-se os índices de Custo-Benefício dos Incentivos Fiscais (ICBIF) desta segunda empresa estudada. 
Relação custo-benefício dos incentivos fiscais: Um estudo baseado na DVA de empresas calçadistas incentivadas Clovis Antônio Kronbauer, Luiz Carlos Schneider, Leandro Lumieri, Fernando Andrade Pereira, João

Ao observar os dados da Tabela 4, percebe-se que o ICB Geral médio da empresa Vulcabrás Azaléia é de 6,11 nos três anos analisados. Assim, para cada $R \$$ 1,00 recebido pela empresa a título de incentivos fiscais, houve a geração média de $\mathrm{R} \$ 6,11$ de valor adicionado. Percebe-se que o maior ICB Geral foi observado em 2007, quando este índice esteve próximo a 8,0, registrando uma redução para 5,46 em 2008 e aumentando novamente em 2009, quando o ICB geral foi de 6,07. Percebe-se que no ano em que a empresa recebeu maior volume de incentivos fiscais, o ICB Geral apresentou-se no menor nível.

Também se observa que nos três anos o ICB Social médio foi de 4,59, o que significa que para cada $R \$ 1,00$ recebido pela empresa a título de incentivos fiscais, houve a distribuição, em média, de $\mathrm{R} \$ 4,59$ de valor adicionado para Pessoal, Encargos Sociais e Tributos, o que pode ser considerado como retorno social. A evolução do ICB Social da empresa Vucabrás Azaléia, seguiu e mesma tendência já comentada no parágrafo anterior, com relação ao ICB Geral.

Tabela 4: Índices Custo-Benefício dos Incentivos Fiscais Recebidos pela Vulcabrás Azaléia

\begin{tabular}{rrrrrrrr}
\hline Ano & $\begin{array}{c}\text { Valor Adic. } \\
\text { Liq. ( 1 ) }\end{array}$ & $\begin{array}{c}\text { Pessoal e } \\
\text { Tributos (2) }\end{array}$ & $\begin{array}{c}\text { Lucros e } \\
\text { Divid. (3) }\end{array}$ & $\begin{array}{r}\text { Incentivo } \\
\text { Fiscal (4) }\end{array}$ & $\begin{array}{c}\text { ICB Geral } \\
(1 / 4)\end{array}$ & $\begin{array}{c}\text { ICB Social } \\
(2 / 4)\end{array}$ & $\begin{array}{c}\text { ICB } \\
\text { Acionist.(3/4) }\end{array}$ \\
\hline 2009 & 1.067 .698 & 755.375 & 137.055 & 175.896 & 6,07 & 4,29 & 0,78 \\
2008 & 999.690 & 735.287 & 173.200 & 183.249 & 5,46 & 4,01 & 0,95 \\
2007 & 536.659 & 465.264 & 24.380 & 67.239 & 7,98 & 6,92 & 0,36 \\
Média & 868.016 & 651.975 & 111.545 & 142.128 & 6,11 & 4,59 & 0,78 \\
\hline
\end{tabular}

Fonte: Elaborado pelos autores com base na Demonstração do Valor Adicionado da Empresa

A partir da Tabela 4, observa-se ainda que o ICB Acionistas apresenta um valor médio de 0,78 no triênio analisado. Isto revela que em relação a cada $R \$ 1,00$ recebido pela empresa a título de incentivos fiscais, coube aos acionistas em média um valor distribuído de $R \$ 0,78$, na forma de lucros retidos e dividendos. No caso da empresa Vulcabrás Azaléia, os incentivos fiscais recebidos revelaram-se superiores aos Lucros retidos e Dividendos Distribuídos, o que pode significar que esta segunda empresa teve uma lucratividade menor que a empresa Grendene. 
Relação custo-benefício dos incentivos fiscais: Um estudo baseado na DVA de empresas calçadistas incentivadas Clovis Antônio Kronbauer, Luiz Carlos Schneider, Leandro Lumieri, Fernando Andrade Pereira, João

Considerando o ICB Geral e o ICB Social da empresa Vulcabrás Azaléia, podese inferir que os incentivos fiscais concedidos geraram um retorno significativo em termos de valor adicionado total e social, sendo que o segundo mostrou-se superior ao da empresa Grendene. O ICB Geral das duas empresas revelou valores muito próximos, sendo que, pelo que já foi referido anteriormente, a empresa Azaléia proporcionou um melhor retorno social, o que se observa a partir do seu ICB social.

Tendo analisado os supostos benefícios gerados pelos incentivos fiscais em termos de valor adicionado distribuído, cabe avaliar os benefícios internos gerados. Para tanto, na sequencia, procede-se na análise dos indicadores de desempenho financeiro e econômico das empresas beneficiadas por incentivos fiscais, e que são objeto deste estudo.

\subsection{Análise econômica e financeira das empresas incentivadas}

\subsubsection{Indicadores da empresa Grendene}

Com base nas Demonstrações Contábeis da empresa Grendene, calculou-se os indicadores econômico-financeiros dos exercícios de 2007 a 2009 da mesma. A partir destes indicadores que são apresentados na Tabela 5, podem-se avaliar os possíveis reflexos dos incentivos fiscais recebidos, no que se refere a benefícios para a situação financeira e econômica da Empresa.

Ao observar os dados da Tabela 5, verifica-se que a empresa apresenta Liquidez Corrente não inferior a 6,00 nos três anos analisados. Assim, para cada $R \$$ 1,00 de dividas de curto prazo a empresa possui recursos de curto prazo de $R \$ 6,00$. A Liquidez Geral apresenta o menor indicador em 2007 de 4,26, ou seja, para cada $R \$$ 1,00 de dividas de curto e longo prazo a empresa possui $R \$ 4,26$ de recursos de curto e longo prazo para pagar estas dívidas. 
Relação custo-benefício dos incentivos fiscais: Um estudo baseado na DVA de empresas calçadistas incentivadas Clovis Antônio Kronbauer, Luiz Carlos Schneider, Leandro Lumieri, Fernando Andrade Pereira, João

Tabela 5: Indicadores Econômico-Financeiros da Empresa Grendene

\begin{tabular}{|c|c|c|c|}
\hline INDICADOR & $\mathbf{2 0 0 9}$ & $\mathbf{2 0 0 8}$ & $\mathbf{2 0 0 7}$ \\
\hline LIQUIDEZ & & & \\
\hline Liquidez Corrente & 6,01 & 6,77 & 7,54 \\
\hline Liquidez Geral & 5,24 & 4,41 & 4,26 \\
\hline ENDIVIDAMENTO & & & \\
\hline Participação de Capital de Terceiros & 0,17 & 0,20 & 0,20 \\
\hline LUCRATIVIDADE & & & \\
\hline Margem Líquida & 0,19 & 0,19 & 0,22 \\
\hline RENTABILIDADE & & & \\
\hline Rentabilidade Sobre Patrimônio Liquido & 0,19 & 0,18 & 0,22 \\
\hline Valor Patrimonial Por Ação & 14,64 & 13,18 & 11,80 \\
\hline Lucro por Ação & 2,72 & 2,39 & 2,61 \\
\hline
\end{tabular}

Fonte: Elaborado com base nas Demonstrações Contábeis de 2009 da Empresa Grendene

O indicador de endividamento nos três anos nunca foi superior a 0,20, indicando que a participação de capital de terceiros sobre o ativo total da empresa é de $R \$ 0,20$ para cada $R \$ 1,00$, ou seja, pode-se concluir que a mesma financia $80 \%$ do seu ativo total com capitais próprios. No que se refere às margens de lucratividade e rentabilidade, ambas são consideradas robustas e lineares nos exercícios apresentados, ou seja, nunca inferiores à $18 \%$ que revela que a empresa tem boa remuneração de recursos próprios.

A boa situação financeira e econômica da empresa permite que a mesma cumpra com todas as suas obrigações fiscais, com seus parceiros, investidores e desta forma contribua com a comunidade na qual está inserida.

Por fim, ao analisar de forma global os indicadores financeiros e econômicos e os indicadores ICBIF da empresa, percebe-se que há certo relacionamento entre estes, visto que a empresa gera valores adicionados significativamente superiores aos benefícios fiscais recebidos e ao mesmo tempo mantêm sua estabilidade financeira e econômica. 
Relação custo-benefício dos incentivos fiscais: Um estudo baseado na DVA de empresas calçadistas incentivadas Clovis Antônio Kronbauer, Luiz Carlos Schneider, Leandro Lumieri, Fernando Andrade Pereira, João

\subsubsection{Indicadores da empresa Vulcabrás Azaléia}

$\mathrm{Na}$ Tabela 6 são apresentados os indicadores financeiros e econômicos da empresa Vulcabrás Azaléia, sendo estes calculados nos exercícios de 2007 a 2009 para que se pudesse analisar a situação da empresa e poder vincular ao estudo em questão de sua evolução favorável ou desfavorável para a geração de distribuição de valor adicionado.

Tabela 6: Indicadores Econômico-Financeiros da Empresa Vulcabrás Azaléia

\begin{tabular}{|c|c|c|c|}
\hline INDICADOR & $\mathbf{2 0 0 9}$ & $\mathbf{2 0 0 8}$ & $\mathbf{2 0 0 7}$ \\
\hline LIQUIDEZ & & & \\
\hline Liquidez Corrente & 1,53 & 1,42 & 0,95 \\
\hline Liquidez Geral & 0,88 & 0,68 & 0,78 \\
\hline ENDIVIDAMENTO & & & \\
\hline Participação de Capital de Terceiros & 0,73 & 0,73 & 0,84 \\
\hline LUCRATIVIDADE & & & \\
\hline Margem Bruta & 0,31 & 0,39 & 0,45 \\
\hline Margem Líquida & 0,09 & 0,11 & $-0,01$ \\
\hline RENTABILIDADE & & & \\
\hline Rentabilidade Sobre Patrimônio Liquido & 0,31 & 0,44 & $-0,06$ \\
\hline Valor Patrimonial Por Ação & 6,25 & 5,57 & 3,12 \\
\hline Lucro por Ação & 1,96 & 2,47 & $-0,17$ \\
\hline
\end{tabular}

Fonte: Elaborada com base nas Demonstrações Contábeis de 2009 da Empresa Vulcabrás Azaléia

Observando os dados da tabela 6, percebe-se que o indicador de Liquidez Corrente teve seu pior índice no ano de 2007, quando ficou menor que 1,0 revelando que para cada $R \$ 1,00$ de divida de curto prazo, a empresa possuía apenas $R \$ 0,95$ de ativos circulantes. Nos anos seguintes observou-se uma recuperação deste indicador, o qual passou para 1,42 em 2008 e 1,53 em 2009, revelando capacidade de liquidez no curto prazo.

A Liquidez Geral apresenta um indicador médio dos três anos analisados de 0,78 . Assim, na média deste período, para cada $R \$ 1,00$ de dividas de curto e longo prazo a empresa possui $R \$ 0,78$ em seu ativo circulante e no realizável de longo 
Relação custo-benefício dos incentivos fiscais: Um estudo baseado na DVA de empresas calçadistas incentivadas Clovis Antônio Kronbauer, Luiz Carlos Schneider, Leandro Lumieri, Fernando Andrade Pereira, João

prazo. Isto revela que no longo prazo a empresa não possui a mesma liquidez revelada pela sua liquidez corrente.

Com relação ao indicador de endividamento, percebe-se a partir da Tabela 6 que no ano de 2007 o mesmo registrou o valor mais elevado chegando a $84 \%$ de participação de capital de terceiros. Nos anos seguintes o endividamento reduziu para $73 \%$ indicando que para cada $R \$ 1,00$ investido no ativo total da empresa em 2008 e 2009, $\mathrm{R} \$ 0,73$ vem de capital de terceiros. Esta estrutura de endividamento da empresa reflete diretamente nos indicadores de liquidez da mesma, o que pode explicar os baixos valores do indicador de liquidez geral.

No que se refere às margens de lucratividade e rentabilidade, observa-se uma discrepância nos percentuais, visto que as margens de lucratividades são muito inferiores à rentabilidade que elas geram. Isto ocorre, possivelmente, pelo fato da empresa ter uma estrutura de capital alavancada basicamente por capital de terceiros, elevando as despesas financeiras e apresentando baixos valores de capitais próprios, os quais permaneceram próximos a $27 \%$ do capital total investido na empresa. Nesta estrutura de capital, as margens líquidas obtidas, mesmo que aparentemente não tão robustas, representam uma expressiva rentabilidade sobre o capital próprio. Assim, mesmo que no ano de 2007 a empresa tenha registrado prejuízo, em 2008 e 2009 ela conseguiu remunerar os capitais próprios em $44 \%$ e $31 \%$, respectivamente, em cada ano.

No caso da empresa Vulcabrás Azaléia, parece evidente que houveram significativos benefícios de natureza econômica para a mesma a partir dos incentivos recebidos, o que se reflete no retorno aos capitais próprios. Percebeu-se, também, que a empresa gerou valores adicionados significativamente superiores aos benefícios fiscais recebidos, mas conseguiu beneficiar em maior proporção sua situação financeira e econômica.

Concluída esta parte da análise, na seção seguinte apresentam-se as informações das receitas de impostos gerados aos municípios incentivadores. 
Relação custo-benefício dos incentivos fiscais: Um estudo baseado na DVA de empresas calçadistas incentivadas Clovis Antônio Kronbauer, Luiz Carlos Schneider, Leandro Lumieri, Fernando Andrade Pereira, João

\subsection{Retorno de impostos aos municípios incentivadores}

Nas Figuras 1 e 2 apresentam-se as informações inerentes as receitas de impostos gerados nos exercícios de 2001 a 2009 nos municípios de Sobral e Horizonte no estado do Ceará, cidades para as quais migraram as empresas Grendene e Vulcabrás Azaléia, respectivamente. As informações de impostos gerados dos exercícios de 2001 a 2009 foram fornecidas pelas prefeituras das referidas cidades. Na Figura 1, apresentada na sequência, pode-se observar a evolução da arrecadação do município de Sobral.

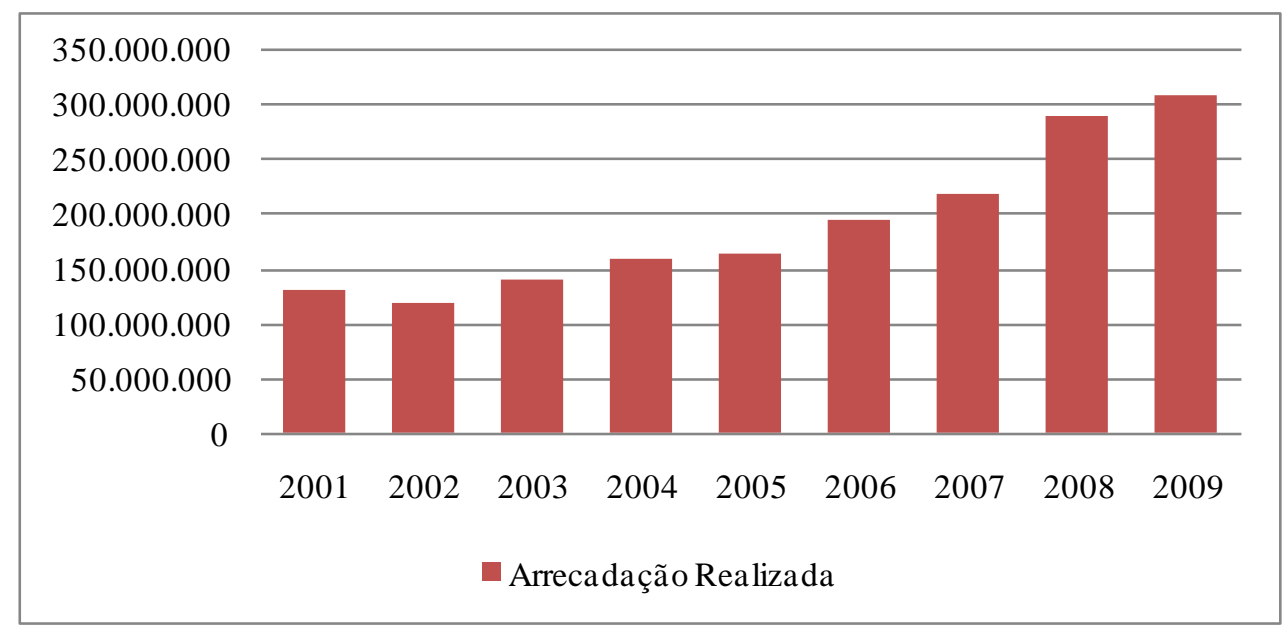

Figura1: Gráfico da arrecadação realizada pelo município de Sobral Fonte: Prefeitura Municipal de Sobral - CE (2011).

$\mathrm{Na}$ Figura 1, observa-se a evolução da arrecadação do município de Sobral sede da empresa Grendene, e se verifica que o município arrecadou em 2001 o valor de $R \$ 131.552 .416,94$, sendo que no final de 2009 esta arrecadação chegou a $R \$$ $308.691 .289,73$ representando um crescimento de $134,65 \%$ no período, com uma evolução média de $11,83 \%$ ao ano. Percebe-se, assim, um significativo crescimento na arrecadação tributária do município de Sobral-CE, num período que coincide com a instalação da empresa Grendene em seu território. Pode-se inferir que a instalação desta empresa, com a concessão de incentivos fiscais, pode ter sido fator relevante para aumento da arrecadação local o que promove o desenvolvimento do entorno em que se instalou a empresa. 
Relação custo-benefício dos incentivos fiscais: Um estudo baseado na DVA de empresas calçadistas incentivadas Clovis Antônio Kronbauer, Luiz Carlos Schneider, Leandro Lumieri, Fernando Andrade Pereira, João

Para avaliar a evolução da arrecadação do município de Horizonte sede da empresa Vulcabrás Azaléia, apresenta-se a Figura 2. Observa-se que em 2001 o município arrecadou $R \$ 15.222 .778,81$ e no final de 2009 esta arrecadação chegou a $\mathrm{R} \$ 70.961 .674,39$ representando um crescimento de $366,15 \%$ no período, com uma evolução média de $23,38 \%$ ao ano. À exemplo do verificado no município de Sobral, percebe-se também um significativo crescimento na arrecadação tributária do município de Horizonte-CE, num período que coincide com a instalação da empresa Vulcabrás Azaléia em seu território. Pode-se inferir que a instalação desta empresa, com a concessão de incentivos fiscais, pode ter sido fator importante para aumento da arrecadação local o que promove o desenvolvimento do entorno em que se instalou a empresa.

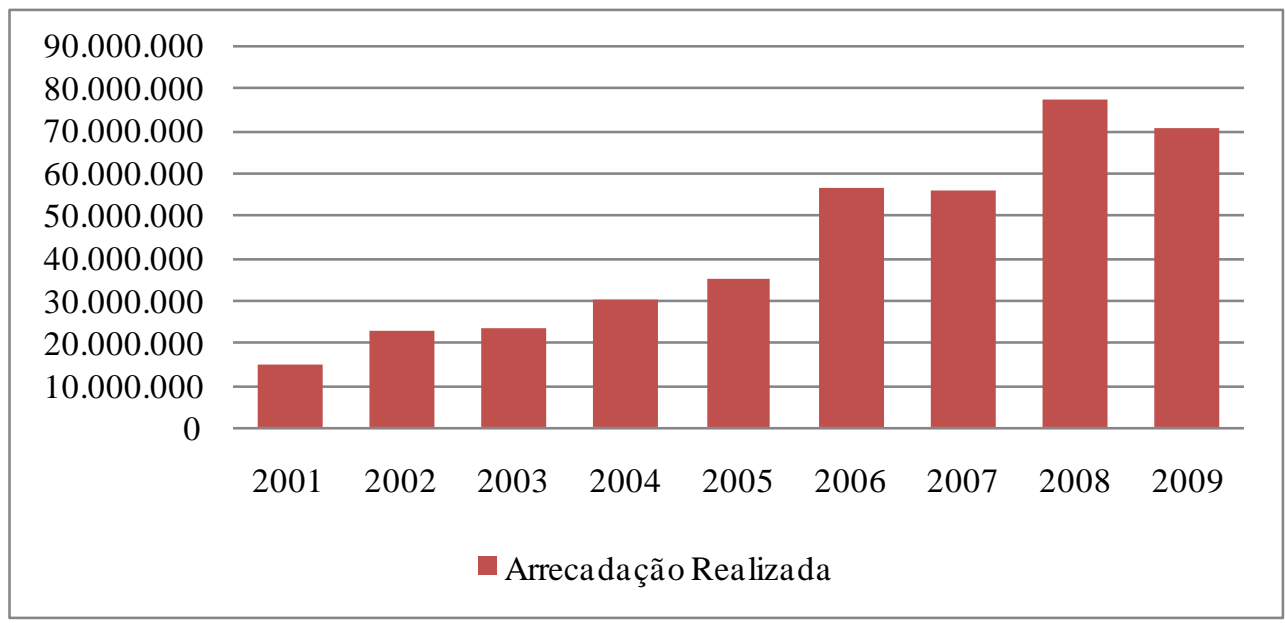

Figura 2: Gráfico da arrecadação realizada pelo município de Horizonte Fonte: Prefeitura Municipal de Horizonte - CE (2011)

Pode-se entender que o aumento de arrecadação constatado em ambos os municípios pode ter sido influenciado pelas empresas incentivadas e que foram objeto do presente estudo. Ao se instalarem nestes municípios, as empresas incentivadas geram benefícios diretos de arrecadação, cabendo ressaltar ainda que sua instalação é fato motivador de atração de diversas outras empresas que fazem parte da cadeia produtiva das mesmas, e que por sua vez também geram receitas e empregos para seus munícipes, promovendo o desenvolvimento da economia local. 
Relação custo-benefício dos incentivos fiscais: Um estudo baseado na DVA de empresas calçadistas incentivadas Clovis Antônio Kronbauer, Luiz Carlos Schneider, Leandro Lumieri, Fernando Andrade Pereira, João

É possível considerar que ao atrair empresas de grande porte como as empresas em questão, estes municípios situam-se no cenário industrial nacional, e no longo prazo possibilitam o desenvolvimento de mão de obra local, adoção de novas tecnologias, ampliação do comércio e criação de valor não apenas de uma forma financeira, mas em termos de inserção social.

\section{CONSIDERAÇÕES FINAIS}

A concessão de incentivos fiscais por parte dos estados é um tema que gera discussões sobre sua eficácia como política econômica e social. No presente estudo, pesquisou-se o retorno propiciado por duas empresas do setor calçadista brasileiro que foram beneficiadas pela concessão de incentivos fiscais e, por conseqüência, migraram para os municípios de Sobral e Horizonte, no estado do Ceará.

Como já referido, as empresas pertencem ao ramo calçadista, que enfrenta ao longo das últimas décadas um alto nível de pressão competitiva. A migração e a consequente instalação destas indústrias em regiões que adotam políticas de incentivos fiscais, tem sido uma forma para que estas se mantenham competitivas. Contudo, a análise dos resultados destas políticas incentivadoras merece estudos, como o realizado nesta pesquisa.

Para contribuir com a análise da relação custo e benefício dos investimentos feitos a título de incentivos fiscais versus o desenvolvimento das regiões incentivadoras, utilizou-se os índices de custo-benefício geral (ICB Geral), social (ICB Social) e de acionistas (ICB Acionistas), calculados a partir das demonstrações de valor adicionado (DVA) das empresas. Verificou-se também a evolução dos impostos gerados nos exercícios de 2001 a 2009 das Prefeituras de Sobral e Horizonte no estado do Ceará sedes das empresas Grendene e Vulcabrás Azaléia, respectivamente.

A partir destes índices e informações, foi possível evidenciar que as empresas retornaram à sociedade local um valor superior ao investido pelo governo a título de incentivos fiscais, o que proporciona oportunidades de desenvolvimento social e 
Relação custo-benefício dos incentivos fiscais: Um estudo baseado na DVA de empresas calçadistas incentivadas Clovis Antônio Kronbauer, Luiz Carlos Schneider, Leandro Lumieri, Fernando Andrade Pereira, João

econômico. Na média dos três anos analisados, o ICB Geral indica que ambas as empresas geraram um valor adicionado superior a seis vezes o valor recebido a título de incentivos fiscais. Percebe-se, também, que as empresas possuem uma situação econômico-financeira estável, ou seja, empresas e municípios obtiveram benefícios com a política de concessão de incentivos fiscais.

Para fins de gestão pública, pode-se considerar que o cálculo do Índice de Custo-Benefício dos Incentivos Fiscais (ICBIF) a partir da DVA, constitui-se em ferramenta que pode contribuir no controle dos benefícios concedidos pelo estado às empresas, gerando informações do retorno econômico-social propiciado pelas mesmas à sociedade.

Outros estudos podem ser realizados no mesmo segmento, ou em outros segmentos, para verificar se as políticas de concessão de incentivos fiscais geram benefícios para os municípios onde as empresas possuem suas unidades industriais instaladas.

\section{REFERÊNCIAS}

COSTEIRA, Maria F. da Silva. (2005). Análise do desempenho econômico, financeiro social e ambiental de empresas: um estudo de empresas do setor alimentício. (Dissertação de Mestrado). Universidade Católica de Santos, Santos-SP.

CPC - COMITÊ DE PRONUNCIAMENTOS CONTÁBEIS. Pronunciamento Técnico CPC-09 Demonstração do Valor Adicionado. Audiência Publica. CPC № 09/2008.

DULCI, Otávio S. (2002). Guerra fiscal, desenvolvimento desigual e relações federativas no Brasil. Revista de Sociologia e Política, Curitiba (PR), 18, p. 95-107, jun.

IUDÍCIBUS, S. de. (2006). Teoria da Contabilidade. (8 ed.). São Paulo: Atlas.

KROETZ, César E. S.; NEUMANN, Marguit; FILIPIN, Roselaine. (2008). Demonstração do Valor Adicionado em Universidades Comunitárias. Revista do Conselho Regional de Contabilidade do Rio Grande do Sul, V.132, P.46-57.

MATARAZZO, Dante C. (2003). Análise Financeira de Balanços, Abordagem Básica e Gerencial. (5 ed.). São Paulo: Atlas.

MATARAZZO, Dante Carmine. (2010). Análise Financeira de Balanços: Abordagem Básica e Gerencial. São Paulo: Atlas. 
Relação custo-benefício dos incentivos fiscais: Um estudo baseado na DVA de empresas calçadistas incentivadas Clovis Antônio Kronbauer, Luiz Carlos Schneider, Leandro Lumieri, Fernando Andrade Pereira, João

MATKIN, D.S.T. (2010). Designing accountable and effective economic development tax incentives - A study of corporate tax credits in Kansas. Performance \& Management Review, Vol. 34, No. 2, December, pp. 166-188.

NASCIMENTO, Sidnei P. (2009). Guerra Fiscal: Uma análise quantitativa para Estados participantes e não participantes. Revista Economia, Brasília (DF), v.10, n.2, p.211237, mai/ago.

PINHO, Diva, B.; VASCONCELOS, Marco A. S. de (org.). (1990). Manual de Economia. São Paulo: Saraiva.

PRADO, S., e Cavalcanti, Carlos E. G. (2000). A Guerra Fiscal no Brasil. São Paulo: Fundap Fapesp; Brasília: IPEA.

RODRIGUES JR., Manuel Salgueiro. (2003). A DVA como Instrumento de Mensuração da Relação Custo Beneficio na Concessão de Incentivos Fiscais: Um Estudo de Caso. In: ANPAD, Anais...

SANTOS, Ariovaldo dos. (1999). Demonstração do Valor Adicionado - DVA- Um instrumento para medição da geração e distribuição de riqueza nas empresas. Tese de Livre Docência, São Paulo: FEA/USP.

SCIPIÃO, Tatiana Teófilo. (2004). Política Industrial para Promoção de Arranjos Produtivos Locais: Um estudo de caso em Marco - Ceará. (Dissertação de Mestrado). UECE. Fortaleza. CE.

SOARES, Luiz A. Valor Adicionado Fiscal - VAF. Secretaria de Estado da Fazenda de Minas Gerais, Superintendência de Arrecadação e Informações Fiscais. Disponível em: <http//: www.portal.cnm.org.br/sites/7200/7299/VAF2009/SlideVAF20095.ppt>. Acesso em: 14/jun/2011.

TINOCO, João E. P. (2011). Balanço Social: Uma Abordagem da Transparência e da Responsabilidade Pública das Organizações. São Paulo: Atlas.

VIOL, Andréa L. (1999). O Fenômeno da Competição Tributária. Aspectos Teóricos e uma Análise do Caso Brasileiro. Monografia vencedora do IV Prêmio de Monografia do Tesouro Nacional. Brasília. Disponível em: <http//:www.tesouro.fazenda.gov.br>. Acesso em: 14/jun/2011.

YIN, R. K. (2010). Estudo de Caso: Planejamento e métodos. Porto Alegre: Bookman.

Data de Submissão: 16/08/2011

Data de Aceite: 29/11/2011 